The following paper posted here is not the official IEEE published version. The final published version of this paper can be found in the Proceedings of the International Electric Machines and Drives Conference (2007 : Antalya, Turkey):pp.1119-1124

Copyright @ 2007 IEEE.

Personal use of this material is permitted. However, permission to reprint/republish this material for advertising or promotional purposes or for creating new collective works for resale or redistribution to servers or lists, or to reuse any copyrighted component of this work in other works must be obtained from the IEEE. 


\title{
Fault Analysis and Remedial Strategies on a Fault- Tolerant Motor Drive with Redundancy
}

\author{
Jingwei Zhu*, Nesimi Ertugrul, and Wen L. Soong \\ School of Electrical and Electronic Engineering \\ The University of Adelaide, Adelaide, Australia, SA 5005 \\ *Email: jingwei@eleceng.adelaide.edu.au
}

\begin{abstract}
Fault-tolerant motor drives are required in a range of safety-critical applications. Using a special motor design and an appropriate inverter topology, brushless permanent magnet AC motor drives can have an effective fault-tolerant capability. Although a single motor fault-tolerant drive system may be sufficient in many critical applications, a higher degree of fault tolerance requires redundancy in the motor system as considered in this paper. This is achieved by using a dual motor module on a common shaft. The simulation model of the entire drive system and the analysis of the various faults are presented in this paper. The effects of fault(s) on the phase current and output torque are provided. Three remedial operating modes are proposed and their features are compared. In addition, an experimental setup was introduced, which is based on dual electrically and magnetically isolated brushless AC motor modules, H-bridge inverters for individual phases and dsPICDEM MCU motor controller.
\end{abstract}

\section{INTRODUCTION}

Fault-tolerant motor drives are important in safety-critical applications such as all-electric aircraft, ships, vehicles and the petrochemical industry. In these applications, a failure of a motor drive may result in loss of human life and property, and may be very costly. Therefore, the motor drives in such applications must be fault-tolerant, and should continue to operate even in the presence of single or multiple faults.

A number of studies have been reported in the literature investigating fault-tolerant motor drives. It is well known that the switched-reluctance motor (SRM) is inherently fault tolerant [1]. However, such motors are not desirable in many applications due to their higher acoustic noise and lower torque density. Brushless permanent magnet (PM) motor drives can have the capability of fault tolerance by minimizing the electrical, magnetic and thermal interaction between the phases and adopting H-bridge inverter circuits for each phase [2-4]. A comparative study carried out in [5] suggested that three-phase brushless PM machines could achieve a similar degree of fault-tolerance as switched-reluctance motors while offering higher torque density and lower acoustic noise.

It should be noted here that although a single motor faulttolerant drive system may be sufficient in many critical applications, it does not offer any redundancy if the entire single motor drive is out of operation. In order to provide redundancy, a dual fault-tolerant PM motor drive system has been proposed in [6]. The performance investigation of this type of motor drive was provided in [7].

Inverter faults and remedial strategies in brushless PM motor drives were investigated in [8,9]. Winding turn-to-turn faults and control methods were studied in [10]. The effect of winding and switch short-circuit faults in star-connected PM motor drives were examined in [11].

The existing fault analysis and investigation are mainly concentrated on the traditional star-connected PM motor drives or on a single three phase PM motor drive with isolated windings. This paper considers a dual motor drive system on a common shaft to introduce redundancy. It performs a study of the effects of open- and short-circuit faults on the phase current and output torque and proposes remedial strategies to compensate for these faults. The experimental setup and motor controller based on a microcontroller are also introduced.

\section{Motor Drive ANd MathematicAl Model}

\section{A. Fault-Tolerant Motor Drive}

As stated above, in order to produce a fault-tolerant brushless PMAC motor drive, it is important to minimize or eliminate the electrical, magnetic and thermal coupling between the motor windings [2]. Thus, a failure in one winding will not affect the operation of the other windings. This may be achieved by physically separating the motor windings and driving each winding using a separate singlephase H-bridge inverter circuit.

Fig. 1 shows a three-phase fault-tolerant brushless PMAC motor drive configuration, where each phase winding occupies two different slots around a single tooth. Fig. 2 illustrates the measured back-EMF waveforms of one of the phases of the test motor. As can be seen in the figure, the back-EMF profile can be approximated to an ideal sinusoidal waveform. Therefore, for simplicity in the simulation and motor control implementation, it is assumed that the back-emfs and reference currents are sinusoidal waveforms for both motor modules.

\section{B. Mathematical Model of the Motor Drive}

The windings of brushless PMAC motors can be modeled by a series equivalent circuit consisting of a resistance $R$, an inductance $L$, and a speed-dependent back-EMF voltage $e(t)$. The computer simulation study includes four equations that describe the dynamic behavior of a motor drive, which are the voltage equation, the electromagnetic torque equation, the equation of motion and the motor speed equation as given below.

$$
v_{i}(t)=R i_{i}(t)+L \frac{d i_{i}(t)}{d t}+e_{i}(t)
$$




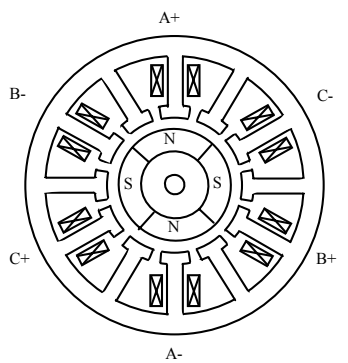

Fig. 1. Winding arrangement of a fault-tolerant brushless PMAC

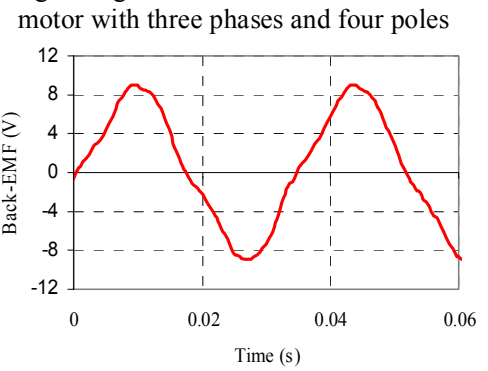

Fig. 2. Motor back-emf waveform at $870 \mathrm{rpm}$

$$
\begin{aligned}
& T_{e}(t)=\frac{1}{\omega(t)} \sum_{i=1}^{n} e_{i}(t) i_{i}(t) \\
& T_{e}(t)=J \frac{d \omega(t)}{d t}+B \omega(t)+T_{L} \\
& \omega(t)=\frac{d \theta(t)}{d t}
\end{aligned}
$$

where $i$ represents the number of phases in the motor drive, the subscript $i=1,2,3,4,5,6$ for the dual three phase motors, $v_{i}(t)$ is the phase voltage, $i_{i}(t)$ is the phase current, $T_{e}(t)$ is the total electromagnetic torque developed by the dual motor system, $\omega(t)$ is the angular speed of the rotor that is common for both motor modules, $\theta(t)$ is the rotor position, $J$ is the polar moment of inertia of the entire system, and $B$ is the damping coefficient.

A Matlab/Simulink based simulation model of the motor drive was developed to investigate the effects of various faults on the phase current and output torque. This simulation model is also used to study the function of the proposed fault remedial strategies which are aimed to compensate the torque loss of various faults.

\section{FAULT ANALYSIS}

The potential faults in a PM motor drive can be classified into a seven major groups: winding open-circuit, winding short-circuit, switch open-circuit, switch short-circuit, power supply fault, position sensor fault and combinations of the above faults.

Amongst these faults, the winding open-circuit and shortcircuit fault, switch open-circuit and short-circuit fault are the most common faults, therefore, this paper emphasizes these faults. A power supply fault in one motor module is analogous to a three-phase fault. If a position sensor fault occurs, the rotor position information can be obtained by an indirect position estimation (sensorless) method.

\section{A. Winding Open-Circuit Fault Analysis}

The winding open-circuit fault is the most common fault, and can be detected by the phase current sensor. This fault is characterized by the phase voltage equaling the voltage of power supply while the phase current remains at zero.

Fig. 3 illustrates the output torque waveform when an opencircuit fault in motor 1 phase $\mathrm{C}$ occurs at $0.2 \mathrm{~s}$. From the figure, it can be seen that the average output torque is decreased after the fault (from $1 \mathrm{pu}$ to $0.833 \mathrm{pu}$ ) and the torque peak-to-peak ripple is higher than healthy operation (from 0 to $40 \%$ ).

\section{B $\quad$ Switch Open-Circuit Fault Analysis}

If one of the switches in the inverter circuit becomes opencircuit and no remedial strategy is adopted, the inverter will operate in unipolar conduction mode, where the phase current can only be controlled for either positive or negative halfcycles. Fig. 4 illustrates the simulation result for this fault. The figure indicates that the average output torque will be decreased to $11 / 12$ of the healthy operation. At the same time, the peak-to-peak torque ripple factor is found to be much higher $(36 \%)$ than the healthy operation $(0 \%)$.

\section{Winding Short-Circuit Fault Analysis}

The winding short-circuit fault is one of the most critical faults in PM motor drives. For the H-bridge inverter configuration, if either the upper switches or lower switches are all gated on, or the DC link is short-circuited, the winding of the fault-tolerant motor would be subjected to a shortcircuit fault. Fig. 5 shows the equivalent circuit of this shortcircuit fault (neglecting the voltage drop of the diode).

During short-circuit operation, a sinusoidal steady-state AC short-circuit fault current will be generated and can be expressed as:

$$
I_{S C}=\frac{E_{0}}{\sqrt{R^{2}+X^{2}}}
$$

For fault-tolerant motors, in order to limit the short-circuit fault current, the inductance is normally chosen as $1 \mathrm{pu}$, resulting in the rated current $I_{0}$ being equal to the high-speed short-circuit current. Thus, at rated speed, the per-unit shortcircuit current can be shown as:

$$
I_{S C}=\frac{1}{\sqrt{R^{2}+1}} p u
$$

The short-circuit fault current in the winding will result in copper loss and drag torque, which can be expressed by equations (7) and (8).

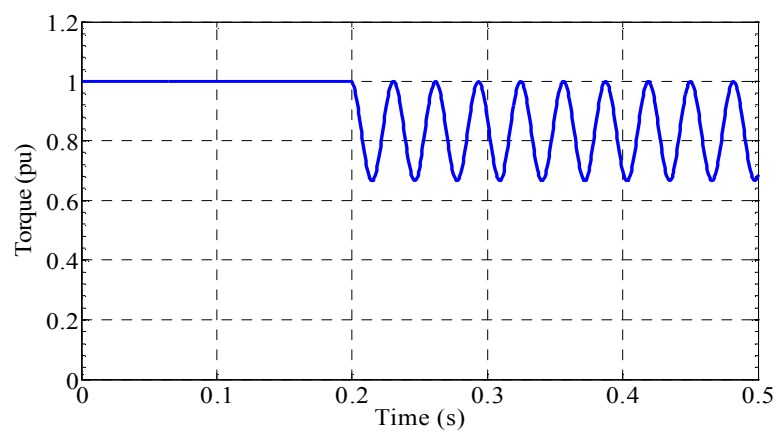

Fig. 3. Output torque waveform when motor 1 phase $\mathrm{C}$ open-circuit fault occurred at $0.2 \mathrm{~s}$ without remedial strategy adopted 


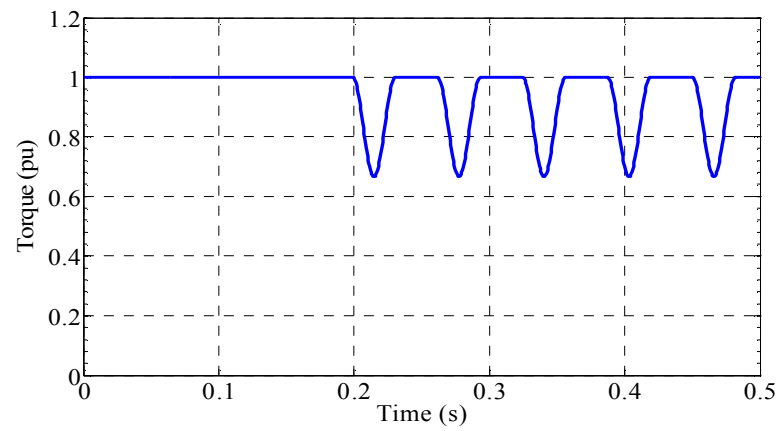

Fig. 4. Output torque waveform when one switch open-circuit fault occurred at $0.2 \mathrm{~s}$ without remedial strategy adopted

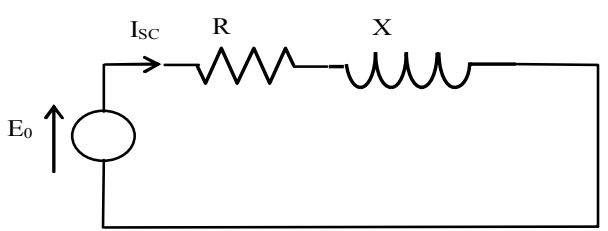

Fig. 5. Equivalent circuit of a winding short-circuit fault

$$
\begin{aligned}
& P_{c u}=I_{S C}^{2} R=\frac{R}{R^{2}+1} \quad p u \\
& T_{\text {drag }}=\frac{R}{R^{2}+1} \quad p u
\end{aligned}
$$

Figs. 6 and 7 show the calculated current and drag torque waveforms respectively at rated speed with a winding shortcircuit fault for the case $R_{p u}=0.05 \mathrm{pu}$, obtained using a PSIM simulation. The short-circuit current is sinusoidal and has an rms value of approximately $1 \mathrm{pu}$.

\section{Switch Short-Circuit Fault Analysis}

If a switch or diode in the H-bridge inverter circuit is shortcircuited, the winding is also subjected to a short-circuit fault through the diode in the other phase leg. The equivalent circuit is shown in Fig. 8 and the short-circuit current and the drag torque waveforms from the PSIM simulations are displayed in Figs. 6 and 7 at rated speed for the case $R_{p u}=0.05 \mathrm{pu}$ (the diode voltage drop is neglected in the simulation). It can be seen that the diode forces the short-circuit fault current to be unidirectional, and that the peak current and peak torque is of the order of twice that for the winding short-circuit case.

Figs. 9 and 10 illustrate the relationship between the shortcircuit current and drag torque with the stator resistance under both winding and switch short-circuit faults. Fig. 9 shows that with the winding short-circuit fault, the rms current is almost constant at $1 \mathrm{pu}$. With the switch short-circuit fault, the rms current is much higher, with a maximum of about $1.7 \mathrm{pu}$ with zero stator resistance, falling to about $1.2 \mathrm{pu}$ with $0.2 \mathrm{pu}$ stator resistance. Fig. 10 shows the average drag torque is also much greater with the switch short-circuit fault, and for instance with $0.1 \mathrm{pu}$ stator resistance, the drag torque with the switch short-circuit fault is about twice that with the winding shortcircuit fault.

From this it is clear that the negative effects on the motor drive under a switch short-circuit fault is worse than that under a winding short-circuit fault. Therefore, if a switch shortcircuit fault occurred in the inverter, it is better to turn on the opposite switch and transform the switch short-circuit fault into winding short-circuit fault. This is a similar conclusion to what has been found with star-connected interior PM machines [11].

\section{Fault Remedial StRategies}

As mentioned above, when a switch open-circuit fault occurs, the inverter can still operate in a unipolar mode with either positive or negative half-cycles of the current. However, for simplicity, it is proposed that all the switches in this phase are turned off after this fault is detected. Thus, the switch open-circuit fault has a similar result to the winding opencircuit fault.

Similarly, if a switch short-circuit fault is detected the corresponding switch in the other phase-leg can be turned on, and the effect of this fault becomes analogous to a winding short-circuit fault. Therefore, as far as the remedial strategy is concerned, the switch short-circuit fault can be treated similarly to a winding short-circuit fault.

A common assumption in this study is that the reactance of windings is $1 \mathrm{pu}$, the resistance of windings is small, and the drag torque of a winding short-circuit fault on the total torque

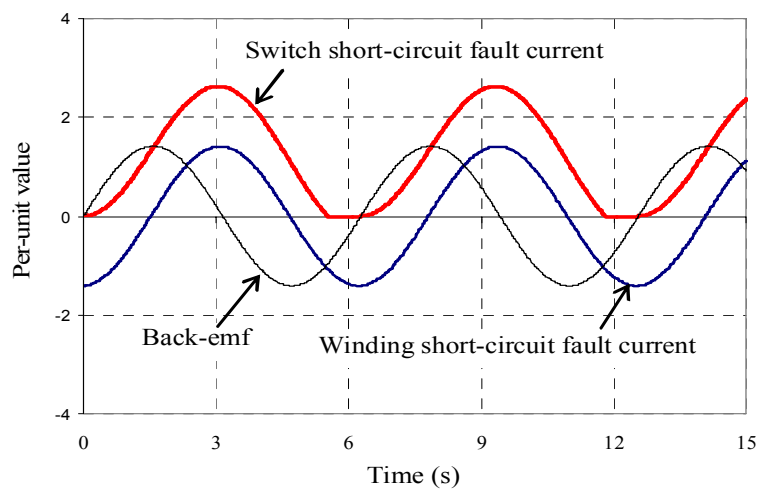

Fig. 6. Back-emf and current waveforms with winding and switch short-circuit faults when $L=1 \mathrm{pu}, R=0.05 \mathrm{pu}$

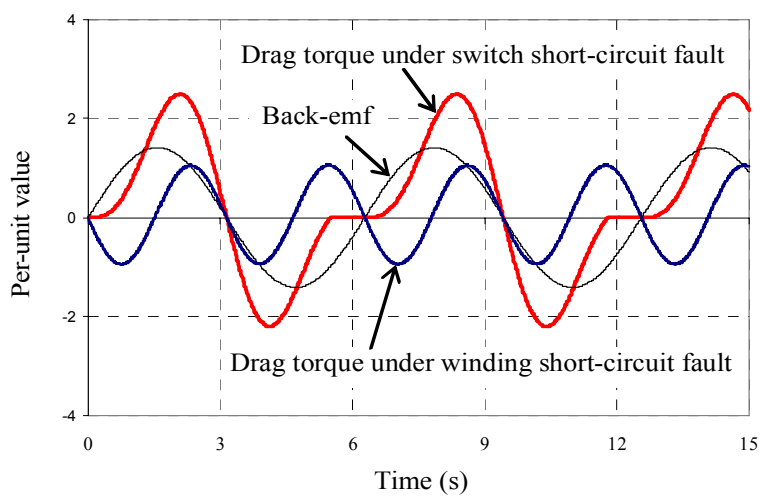

Fig. 7. Back-emf and drag torque waveforms with winding and switch short-circuit faults when $L=1 \mathrm{pu}, R=0.05 \mathrm{pu}$

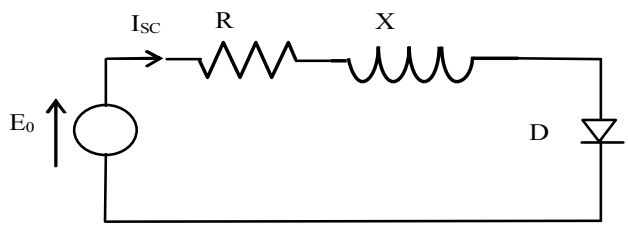

Fig. 8. Equivalent circuit of switch short-circuit fault 
can be neglected. Under this assumption, all the faults can be classified as one-phase, two-phase and three-phase faults.

Using the simulation results of the motor drive, it was concluded that the average output torque decreased by a factor of $m / n$ (where $n$ and $m$ represent the total number of phases in the motor drive and the number of faulty phases respectively). The primary target of the dual fault tolerant motor drive is to provide rated (or near rated) torque even under faulted operation. Therefore, since the output torque is proportional to the phase current, the only option to maintain rated output torque under faulted conditions is to increase the current in the healthy phases.

Three remedial strategies are proposed to generate rated output torque with the loss of one phase: (1) increase the amplitude of the sinusoidal reference current equally in the remaining healthy phases; (2) choose the reference current waveform to maintain rated output torque with zero torque ripple and minimum copper loss; (3) for dual three-phase motor drives, if one phase has a fault, double the current in the same phase of the other motor module. The output torque ripple factor and copper loss are different with different remedial strategies. In following paragraphs, the features of these methods will be discussed in detail.

\section{A Remedial Strategies for a Single Motor Drive}

For a single three-phase motor drive, in healthy operation, if the back-emf and phase current are ideal sinusoidal waveforms, the total output torque and copper loss can be expressed as follows:

$$
T_{s 0}=\frac{3}{2} K_{m} I_{m}
$$

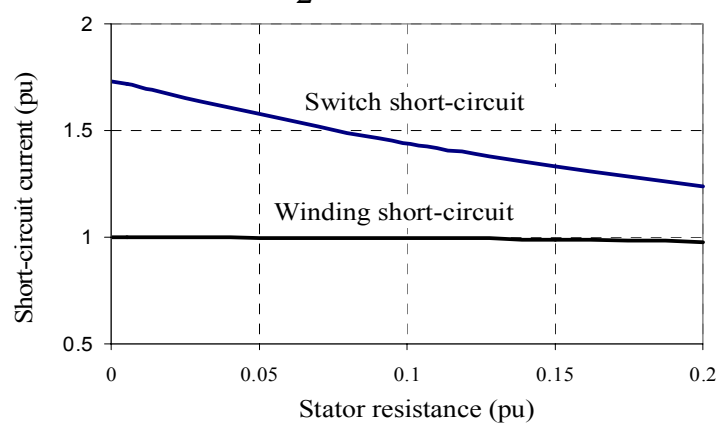

Fig. 9. The relationship between the rms short-circuit current and the stator resistance for short-circuit faults.

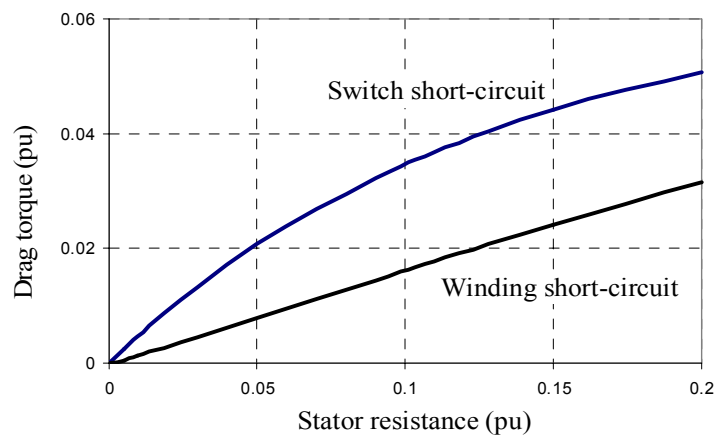

Fig. 10. The relationship between the drag torque and the stator resistance for short-circuit faults.

$$
P_{\text {cus } 0}=\frac{3}{2} R I_{m}^{2}
$$

where $K_{m}$ represents the motor back-emf constant, $I_{m}$ is the peak value of the phase current, and $R$ is the resistance of the phase windings.

If a fault occurs in phase $\mathrm{C}$, in order to maintain rated output torque, remedial strategy 1 simply increases the magnitudes of the sinusoidal reference currents for phases $\mathrm{A}$ and $\mathrm{B}$ by $50 \%$. The total output torque is:

$$
T=T_{0}\left[1+\frac{1}{2} \sin (2 \omega t-\pi / 6)\right]
$$

From (11), it can be seen that the peak-to-peak torque ripple factor in this remedial strategy is $100 \%$ (equal to the average torque). Similarly, the total copper loss in this situation can be calculated as $50 \%$ higher than the healthy operating mode.

With remedial strategy 2, the reference current waveforms for phase $\mathrm{A}$ and $\mathrm{B}, i_{a}(t)$ and $i_{b}(t)$, are chosen to produce ideally zero torque ripple with the minimum total copper loss. It can be shown that under these conditions, the instantaneous values of $i_{a}(t)$ and $i_{b}(t)$ depend only on the instantaneous back-emf values in phases $\mathrm{A}$ and $\mathrm{B}, e_{a}(t)$ and $e_{b}(t)$, the reference torque $T_{s 0}$ and the mechanical rotor speed $\omega_{\mathrm{m}}$, and can be given as:

$$
\begin{aligned}
& i_{a}(t)=\frac{T_{s 0} \omega_{m}}{e_{a}^{2}(t)+e_{b}^{2}(t)} e_{a}(t) \\
& i_{b}(t)=\frac{T_{s 0} \omega_{m}}{e_{a}^{2}(t)+e_{b}^{2}(t)} e_{b}(t)
\end{aligned}
$$

This shows that for minimum copper loss, the instantaneous phase currents should be chosen proportionally to the instantaneous back-emf value. In general, this will result in non-sinusoidal reference currents. From these equations, the instantaneous copper loss can be calculated as:

$$
\frac{P_{c u}}{P_{c u s} 0}=\frac{3}{2} \cdot \frac{1}{\sin ^{2}(\omega t)+\sin ^{2}(\omega t-(2 / 3) \pi)}
$$

where $\omega$ is the electrical speed.

Figs. 11 and 12 provide the simulation waveforms of backemf voltage, phase current, output torque and copper loss for this remedial strategy after the phase $\mathrm{C}$ open-circuit fault. Fig. 11 shows that the phase current waveforms are significantly distorted and show large peaks in the regions where phase $\mathrm{C}$ would normally be generating a significant output torque. From the simulation, it can be concluded that after this remedial strategy is adopted, the output torque is kept constant as in the healthy operation, while the total average copper loss is increased by about $73 \%$ above that for healthy operation which should be compared with the theoretical minimum value of $50 \%$ for strategy 1 which has a high ripple torque.

\section{B Remedial Strategies in a Dual Motor Drive}

For a dual motor drive, in healthy operation, if the waveforms of back-emf and phase currents are ideal sinusoids as in the single motor drive, the total output torque $T_{d 0}$ and copper loss $P_{\text {cud } 0}$ are twice that of the single motor drive.

A common remedial strategy for phase faults is to increase the average current in the remaining healthy phases (remedial 


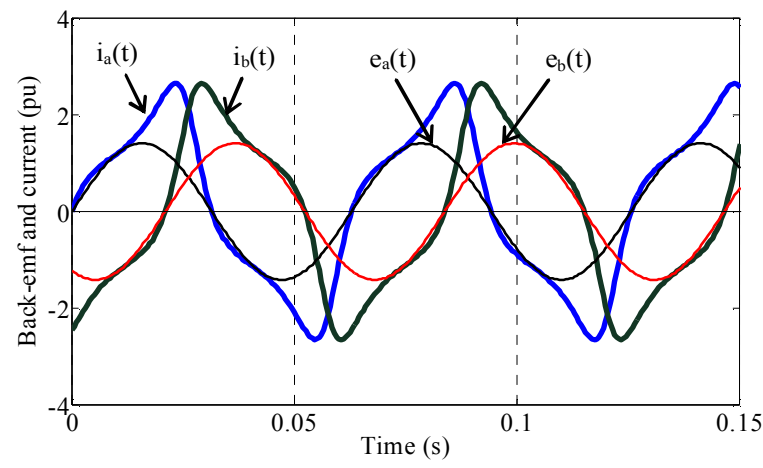

Fig. 11. Back-emf and current waveforms with the phase $\mathrm{C}$ open-circuit fault in a single motor drive with remedial strategy 2

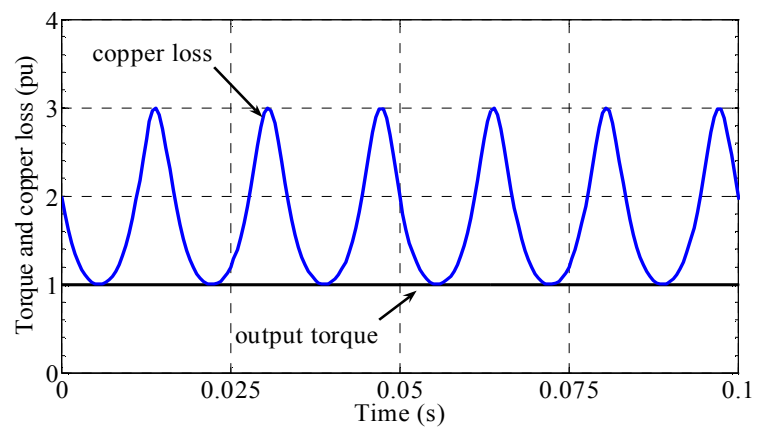

Fig. 12. Output torque and copper loss waveforms with the phase $\mathrm{C}$ opencircuit fault in a single motor drive with remedial strategy 2

strategy 1). For a dual motor drive, to obtain the same output torque $T_{d 0}$, with a one-phase fault, the current in the healthy phases must be 1.2 times the rated current. Furthermore, for a two-phase fault, the current in the healthy phases is 1.5 times of the rated current, and for three-phase fault or one complete motor drive fault, the current in the healthy phases should be two times rated current. The output torque ripple factor and copper loss under different fault conditions are displayed in Table I.

For a one-phase fault (for example motor 1 phase $\mathrm{C}$ fault) in a dual motor drive, the optimal current control strategy can be utilized (remedial strategy 2). In order to limit the peak current in phases $\mathrm{A}$ and $\mathrm{B}$ of motor module 1 , the sinusoidal reference current of the phases in motor module 2 are increased to 1.2 times that for healthy operation. Under this remedial strategy, the optimal phase currents in motor module 1 and the total instantaneous copper loss of motor drive are as follows:

$$
\begin{aligned}
i_{1 a}(t) & =\frac{\frac{2}{5} T_{d 0} \omega_{m}}{e_{1 a}^{2}(t)+e_{1 b}^{2}(t)} e_{1 a}(t) \\
i_{1 b}(t) & =\frac{\frac{2}{5} T_{d 0} \omega_{m}}{e_{1 a}^{2}(t)+e_{1 b}^{2}(t)} e_{1 b}(t) \\
\frac{P_{c u}}{P_{c u d} 0} & =\frac{12}{25} \cdot \frac{1}{\sin ^{2}(\omega t)+\sin ^{2}(\omega t-(2 / 3) \pi)}+\frac{18}{25}
\end{aligned}
$$

Figs. 13 and 14 provide the simulation waveforms of the phase current, output torque and copper loss for this remedial strategy after an open-circuit fault occurs in phase $\mathrm{C}$ of motor module 1. From the simulation, it was found that after the remedial strategy is adopted, the output torque is constant as in healthy operation, while the average copper loss is increased by $27 \%$ compared to healthy operation versus $20 \%$ for strategy 1 .

In the dual motor drive, with a one-phase fault it is possible to double the current in the corresponding phase in the second motor module to compensate the torque loss due to the fault (remedial strategy 3). In this remedial strategy mode, the output torque ripple factor is zero. However, the winding copper loss in this phase will be four times its rated value.

For a dual motor drive, with the three-phase fault or one motor complete fault, the only way to generate the rated torque is to double the current in the other motor module.

The comparison of the features of the different fault remedial strategies are summarized in Table I which shows the torque ripple, total copper loss and the highest phase copper loss. The latter value is important as it relates to the maximum winding temperature in the machine. From the table, the following conclusions can be obtained: (1) remedial strategy 1 is the simplest mode. However, this strategy has a relatively higher torque ripple factor both in single and dual motor drives; (2) remedial strategy 2 is more complex to implement but has zero torque ripple factor and little higher copper loss than remedial strategy 1; (3) for the dual motor drive, remedial strategy 3 is a simplest way to get zero torque ripple factor, although at the cost of the highest copper loss.

\section{EXPERIMENTAL SETUP}

Fig. 15 illustrates the experimental setup developed in this study, which includes a DC load machine and two faulttolerant brushless PMAC motor modules with surfacemounted PM rotors, all connected on a common shaft. Fig. 16

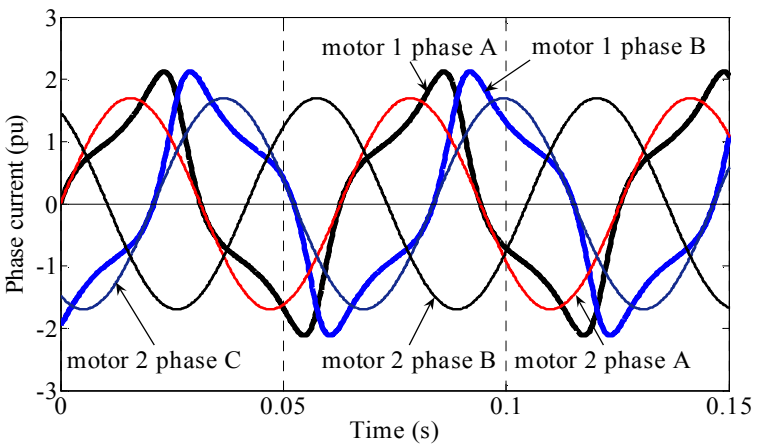

Fig. 13. Phase current waveforms with motor module 1 phase $\mathrm{C}$ open-circuit fault with remedial strategy model 2

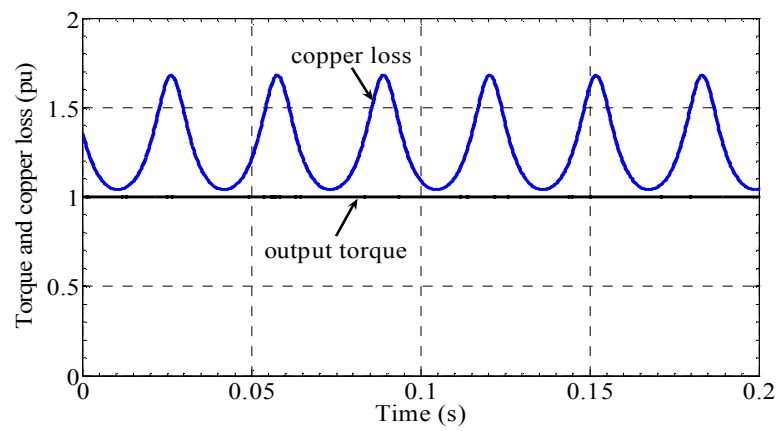

Fig. 14. Output torque and copper loss waveforms with motor module 1 phase $\mathrm{C}$ open-circuit fault with remedial strategy mode 2 
shows one of the inverter controllers and also a phase current and voltage measurement board. As indicated previously, the motor drive contains separate H-bridge inverter circuits for each phase. The two motor modules are also powered from separate power supplies.

Two Microchip dsPICDEM MC1 controllers are selected for the motor controller. The dsPIC30F6011 digital signal controller is installed on the motor control board, which has a sixteen input $\mathrm{A} / \mathrm{D}$ converter, eight PWM outputs, an encoder input, five 16-bit timers and more than 20 digital input and output ports. The function of the controller includes rotor position measurement, phase current and voltage measurement, fault detection and identification, and the implementation of the motor control algorithm. The two controllers also communicate with each other to exchange control and fault information.

\section{CONCLUSUON}

This paper considered a fault-tolerant motor drive that uses two electrically and magnetically uncoupled three-phase brushless PM motors, which offers motor redundancy. The effect of different faults on the phase current and output torque was discussed in this paper.

It was shown that switch or diode short-circuit faults have a greater impact on the motor drive performance than winding short-circuit faults, and that this impact is dependent on the phase resistance.

Three remedial strategies were proposed to compensate for the loss of one or more phases, and the tradeoffs in their performance between output torque ripple and copper loss was examined. Using the "optimal" reference current waveshape was found to give zero torque ripple with only a modest increase in copper loss comparing with the minimum possible value.

An experimental implementation based on two Microchip dsPIC30F6010 controllers was also explained in this paper. The real time behavior of the entire fault-tolerant motor drive with synthetic faults using the hardware developed will be investigated and reported in future studies.

\section{REFERENCES}

[1] C. M. Stephens, "Fault detection and management system for faulttolerant switched reluctance motor drives", IEEE Transactions on Industry Applications, Vol. 27(6), Nov.-Dec. 1991, pp. 1098-1102.

[2] B. C. Mecrow, A. G. Jack, J. A. Haylock, J. Coles, "Fault-tolerant permanent magnet machine drives", IEE Proceedings on Electric Power
Applications, Vol. 143(6), Nov. 1996, pp. 437-442.

[3] J. A. Haylock, B. C. Mecrow, A. G. Jack, and D. J. Atkinson, "Operation of a fault tolerant PM drive for an aerospace fuel pump application", IEE Proceedings on Electric Power Applications, Vol. 145(5), September 1998, pp. 441-448.

[4] B. C. Mecrow, A. G. Jack, D. J. Atkinson and S. R. Green, "Design and testing of a four-phase fault-tolerant permanent-magnet machine for an engine fuel pump", IEEE Transactions on Energy Conversion, Vol. 19(4), Dec. 2004, pp. 671-678.

[5] A. G. Jack, B. C. Mecrow, and J. A. Haylock, "A comparative study of permanent magnet and switched reluctance motors for high performance fault-tolerant applications", IEEE Transactions on Industry Applications, Vol. 32(4), July-Aug. 1996, pp. 889-895.

[6] N. Ertugrul, W. Soong, G. Dostal, and D. Saxon, "Fault tolerant motor drive system with redundancy for critical application", IEEE Power Electronics Specialists Conference, Cairns, June 2002.

[7] J. Zhu, N. Ertugrul, and W. Soong, "Performance Investigation of a Fault-Tolerant Brushless Permanent Magnet AC Motor Drive", The CES/IEEE International Power Electronics and Motion Control Conference, Shanghai, Aug. 2006.

[8] S. Bolognani, M. Zordan, and M. Zigliotto, "Experimental fault-tolerant control of a PMSM drive", IEEE Transactions on Industrial Electronics, Vol. 47(5), Oct. 2000, pp. 1134-1141.

[9] B. G. Park, T. S. Kim, J. S. Ryu anf D. S. Gyun, "Fault Tolerant Strategies for BLDC Motor Drives under Switch Faults", IEEE IAS Annual Meeting, Tampa, Florida, Oct. 2006

[10] C. Gerada, K. Bradley, and M. Sumner, "Winding turn-to-turn faults in permanent magnet synchronous machine drives", IEEE IAS Annual Meeting, Hong Kong, Oct. 2005.

[11] B. Welchko, T. Jahns, W. Soong, and J. Nagashima, "IPM Synchronous Machine Drive Response to Symmetrical and Asymmetrical Short Circuit Faults", IEEE Transactions on Energy Conversion, Vol. 18, No. 2, June 2003, pp. 291-298.

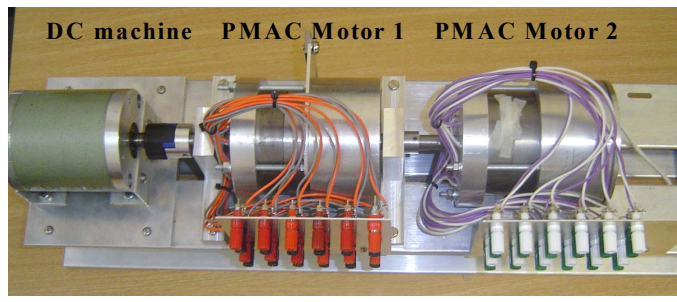

Fig. 15. Motor drive test setup

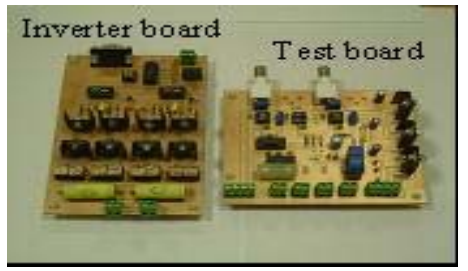

Fig. 16. Inverter and parameter test board

TABLE I

Feature Comparision Of DifFerent Remedial Strategy modes

\begin{tabular}{|c|c|c|c|c|c|}
\hline & Operation modes & $\begin{array}{c}\text { Torque ripple } \\
(\%)\end{array}$ & $\begin{array}{c}\text { Total copper } \\
\text { loss (pu) }\end{array}$ & $\begin{array}{l}\text { Maximum phase } \\
\text { copper loss (pu) }\end{array}$ & Realization \\
\hline $\begin{array}{l}\text { Single motor drive } \\
\text { one-phase fault }\end{array}$ & Remedial strategy 1 & 100 & 1.5 & 2.25 & simple \\
\hline \multirow{3}{*}{$\begin{array}{l}\text { Dual motor drive } \\
\text { one-phase fault }\end{array}$} & Healthy operation & 0 & 1 & 1 & \\
\hline & Remedial strategy 1 & 40 & 1.2 & 1.44 & simple \\
\hline & Remedial strategy 2 & 0 & 1.27 & 1.66 & more complex \\
\hline
\end{tabular}

